\title{
Bilateral maculopathy simulating 'cherry-red spot' in a patient with Crohn's disease
}

\author{
Y. YASSUR, M. SNIR, S. MELAMED, AND I. BEN-SIRA \\ From the Department of Ophthalmology, Beilinson Medical Center, and \\ Tel Aviv University Medical School, Petah Tikva, Israel
}

SUMmARY A 23-year-old man suffering from Crohn's disease developed a bilateral maculopathy simulating 'cherry-red spot' with vision impairment and normal electroretinogram during total parenteral hyperalimentation, when copper and zinc serum levels were considerably decreased. The maculopathy rapidly subsided after cessation of the parenteral hyperalimentation and the addition of copper and zinc. The cause of this maculopathy may be ocular involvement as part of the systemic disease owing to storage of the supplementary free amines and intravenous lipids, and the deficiency of zinc and copper.

Crohn's disease is an intestinal disorder which may be accompanied by systemic features such as arthritis, ${ }^{12}$ impaired liver function, ${ }^{34}$ lymphadenopathy, ${ }^{1}$ haematological disorders, ${ }^{3-6}$ and various ocular manifestations. ${ }^{1-3}$ 7-10 This ocular involvement occurs in $3.6 \%-9.6 \%$ of cases, ${ }^{12}$ the anterior segment being the most frequently affected. Features such as corneal ulcer, ${ }^{71}$ blepharokeratitis, ${ }^{27}$ conjunctivitis, ${ }^{7}$ episcleritis, ${ }^{127}$ and uveitis ${ }^{278}$ have been reported. Some authors have also described posterior segment involvement, including choroiditis, ${ }^{9}$ retinal vasculitis, ${ }^{910}$ exudative retinal detachment, ${ }^{1}$ optic neuritis, ${ }^{10}$ macular oedema and haemorrhages, ${ }^{17}$ and central serous retinopathy. ${ }^{1}$

The present report describes a patient with Crohn's disease who was treated with total parenteral nutrition and developed a rapid visual impairment with a bilateral maculopathy simulating 'cherry-red spot'. To the best of our knowledge it is the first case of such a macular involvement in Crohn's disease to be described in the ophthalmic literature.

\section{Case report}

A 23-year-old male known to be suffering from Crohn's disease was admitted to hospital for recurrent abdominal pain, loss of weight $(7 \mathrm{~kg})$, and fever $\left(39^{\circ} \mathrm{C}\right)$. Blood pressure was normal. Gastrointestinal examination disclosed progressive intestinal narrowing, and fistula formation. On admission his serum albumin level was $3.0 \mathrm{~g} / 100 \mathrm{ml}$

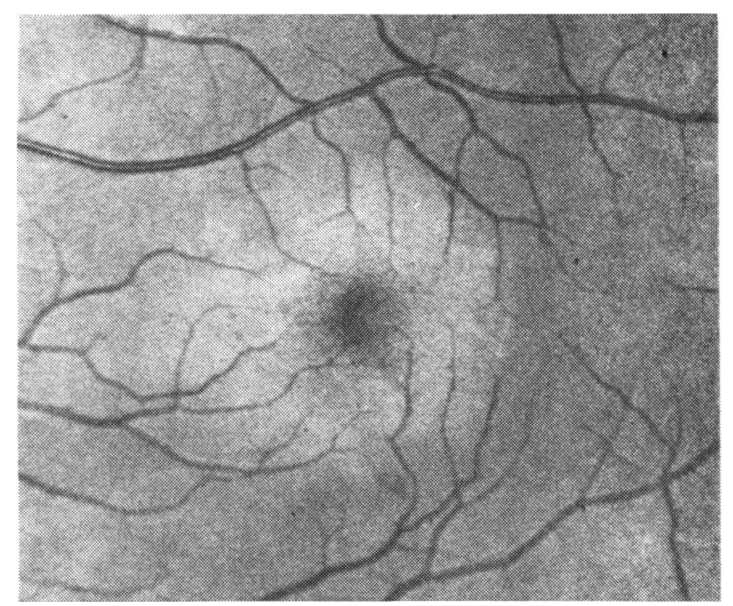

Fig. 1 Left eye: a cherry-red spot maculopathy with white swelling at the posterior pole. The right eye appears the same.

$(30 \mathrm{~g} / 1)$, and total parenteral nutrition was therefore started. The total calorie intake was equivalent to $4000-5000 \mathrm{kcal} / \mathrm{day}$. The patient responded favourably to the treatment. He gained $10 \mathrm{~kg}$ during 3 weeks, and his serum albumin level reached $4 \cdot 2$ $\mathrm{g} / 100 \mathrm{ml}(42 \mathrm{~g} / \mathrm{l})$. The SGOT level was raised to $150 \mathrm{U}$ (normal $\leqslant 40 \mathrm{U}$ ), but other liver functions were completely normal. However, follicular dermatitis developed on the face, neck, and pubis, and several days later a rapid decline of visual acuity appeared in both eyes.

Ophthalmological examination at this stage showed his visual acuity to be down to $6 / 30$ in both 


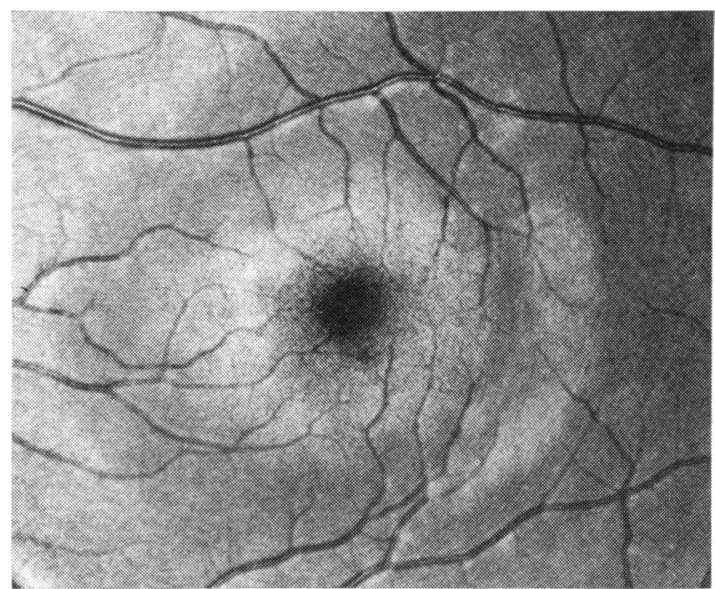

Fig. 2 Left eye: a monochromatic light photograph at $510 \mathrm{~nm}$ wavelength illustrating the affected area around the macula. The affected zone is the internal retinal layers. The right eye appears the same.

eyes. Intraocular pressure and biomicroscopic examination showed no abnormalities. Fundus examination revealed normal optic discs and retinal periphery in both eyes, but there was a bilateral macular lesion, which appeared as a pale swelling resembling a cherry-red spot (Fig. 1). The macular lesion was best demonstrated by stereoscopic monochromatic light photography at $510 \mathrm{~nm}$ wavelength. This revealed that the maculopathy affected the zone of the ganglion cells and probably the adjacent layers too (Fig. 2).

Fluorescein angiography detected a normal pattern of the macular area throughout the early as well as the late phases of the angiogram (Fig. 3). Kinetic perimetry (Figs. 4, 5) and static perimetry (Figs. 6, 7) demonstrated central and paracentral scotoma in both eyes. The ERG was normal.

The rest of the laboratory tests such as blood count, haemoglobin concentration, blood viscosity, haematocrit, bleeding time, prothrombin time, thrombocytes, serum lipids, cholesterol, $\mathrm{B}_{12}$, folic acid, and autoimmune factors were normal. However, the levels of serum zinc and copper and of alkaline phosphatase were considerably decreased. $\mathrm{Zn}$ was $30 \mu \mathrm{g} / 100 \mathrm{ml}(300 \mu \mathrm{g} / \mathrm{l}$ ) (normal, 90-160 $\mu \mathrm{g} / 100 \mathrm{ml} \quad(900-1600 \mu \mathrm{g} / \mathrm{l}), \mathrm{Cu}$ was $70 \mu \mathrm{g} / 100 \mathrm{ml}$ (normal, $\quad 90-160 \mu \mathrm{g} / 100 \mathrm{ml} \quad(900-1600 \mu \mathrm{g} / \mathrm{l})$, and

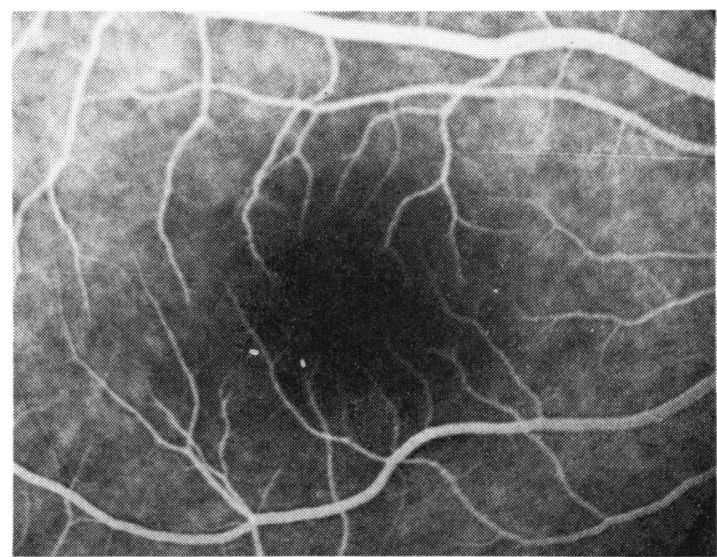

Fig. 3 Fluorescein angiography, venous phase showing a normal pattern.

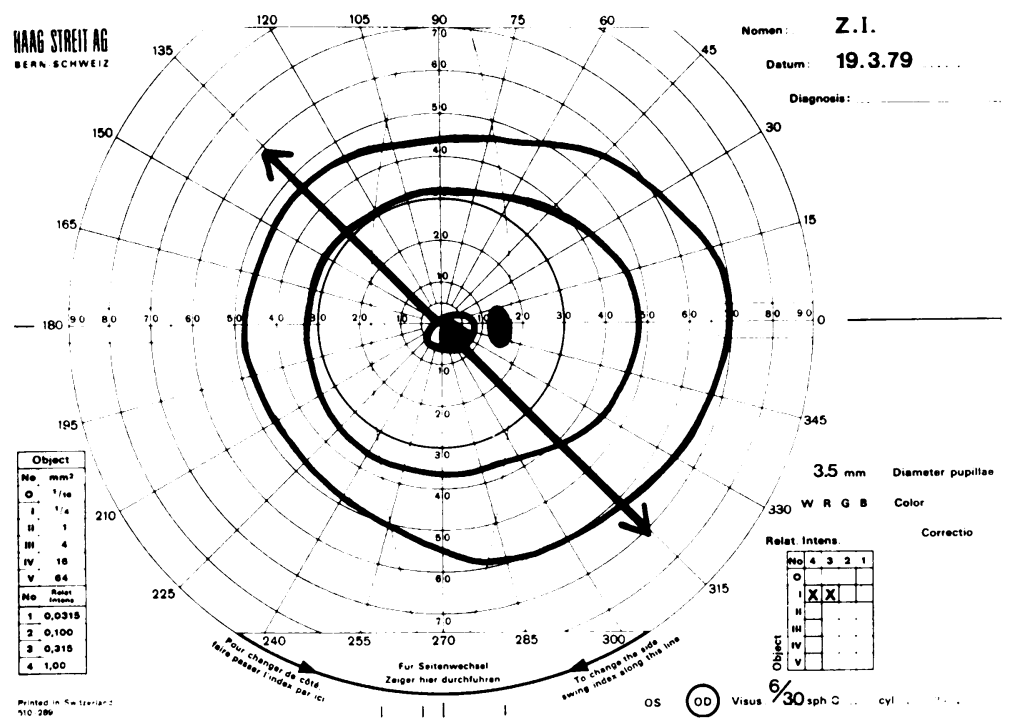

Fig. 4 Kinetic perimetry of the right eye demonstrating a central and paracentral scotoma. 
Fig. 5 Kinetic perimetry of the left eye also demonstrating a central and paracentral scotoma.

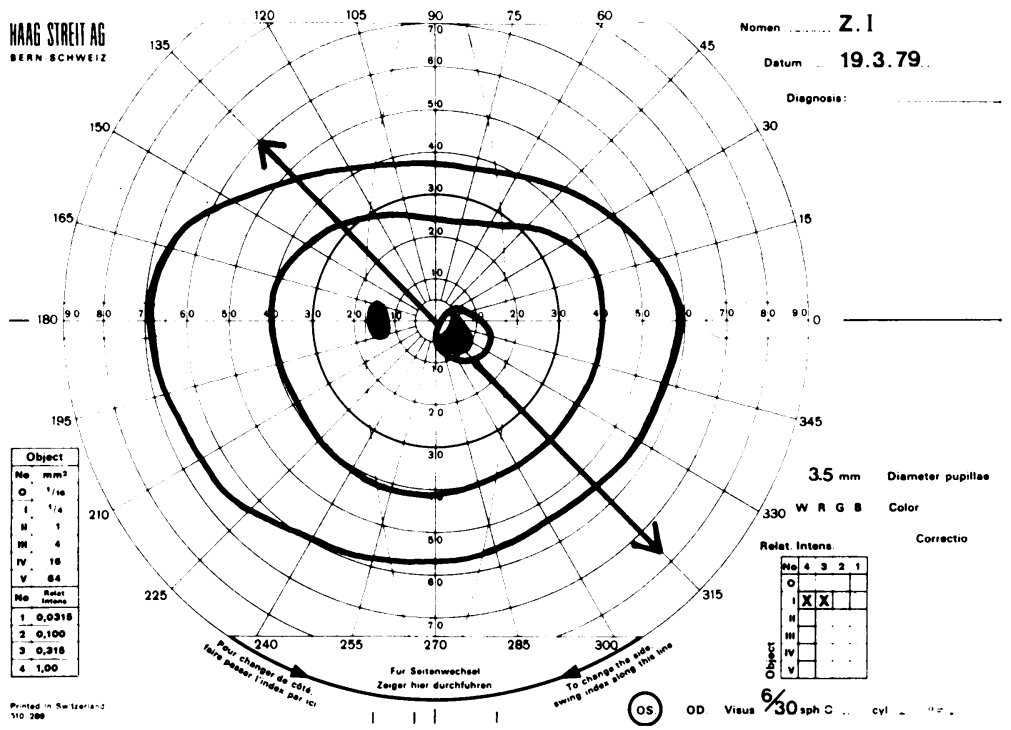

alkaline phosphatase was $35 \mathrm{IU} / 1$ (normal, 40-85 IU / l).

At this stage the parenteral nutrition was discontinued, and treatment was started with anticoagulants (heparin $5000 \mathrm{U}$ twice a day and dipyridamole forte $225 \mathrm{mg} /$ day), papaverine $0.08 \mathrm{mg} / \mathrm{l}$, and dextran 40 intravenously together with supplementary zinc and cuprum. The maintenance dose of the steroid was continued.

Eighteen hours later a regression of the macular lesion in both eyes was noted. This regression continued for several days, with gradual improvement in visual acuity. After 2 weeks the visual acuity was $6 / 6$ in both eyes, no signs of maculopathy could be detected (Fig. 8), and the visual fields returned completely to normal. Serum zinc, copper, and alkaline phosphatase measurements were normal $(100 \mu \mathrm{g} / 100 \mathrm{ml}(1000 \mu \mathrm{g} / \mathrm{l}), 150 \mu \mathrm{g} / 100 \mathrm{ml}(1500 \mu \mathrm{g} / \mathrm{l})$, and $80 \mathrm{IU} / 1$ respectively).

\section{Discussion}

Several possible mechanisms for the ocular involvement in Crohn's disease have been suggested. Among them are hypersensitivity reaction based on autoimmune mechanism ${ }^{11}$ and a greater incidence of thromboembolic phenomena. ${ }^{35}$ No absolute correlation has been shown to exist between the
Fig. 6 Static perimetry of the right eye at the meridian 135 315 demonstrating a central and paracentral scotoma.

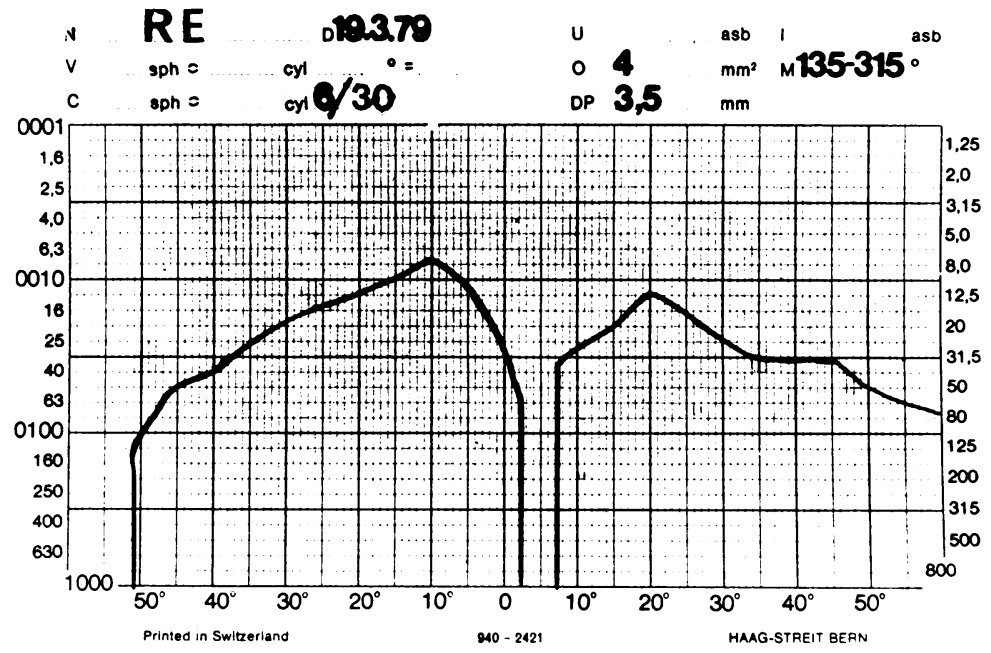




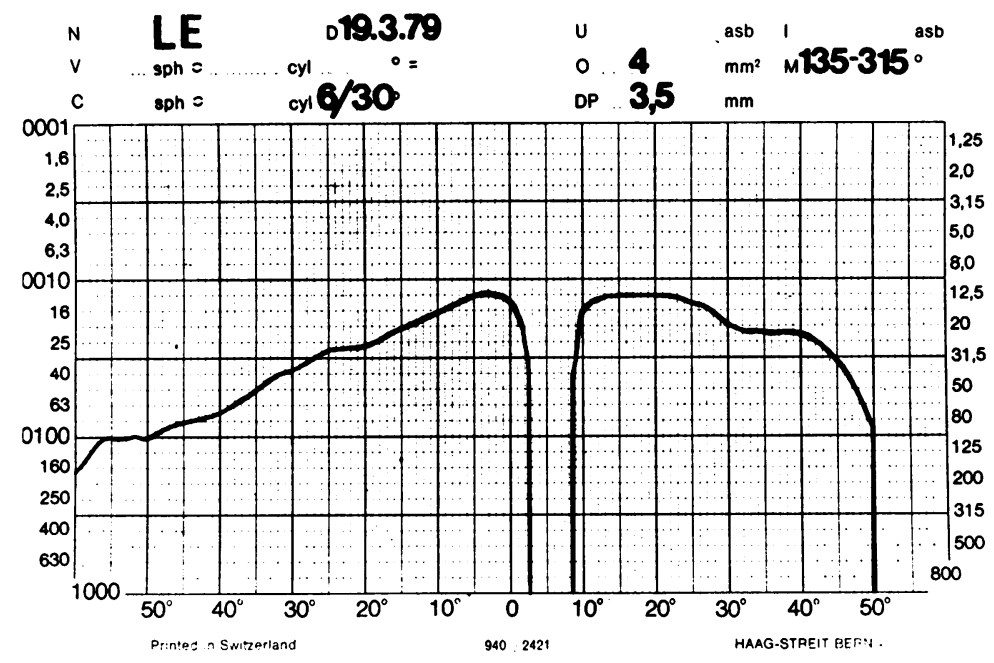

Fig. 7 Static perimetry of the left eye at the meridian $135-315$ demonstrating a central and paracentral scotoma.

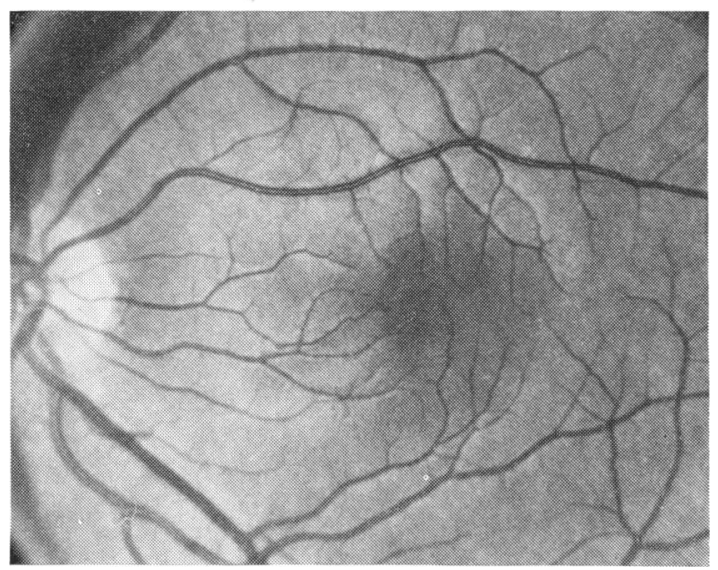

Fig. 8 Photograph of the left macula after regression of the lesion. No signs of maculopathy can be detected. The right macula also had a complete regression of the lesion and looked normal.

severity of the systemic disease and the appearance of the ocular manifestations. ${ }^{7}$

Cherry-red spot was described in various metabolic and neurological disorders ${ }^{9}$ as well as in retinal artery occlusion.

In the present case there was no correlation between the systemic exacerbation and the macular involvement. On the contrary, the macular involvement developed during a phase of systemic improvement. The possibility of bilateral thromboembolism in this patient cannot be completely ruled out. However, a simultaneous bilateral arterial occlusion seems rather unlikely. In addition, the clinical picture was not really compatible with such a vascular accident.
The macular involvement occurred during the parenteral nutrition and cleared up after the cessation of this hyperalimentation and the addition of trace elements. This may suggest one or both of the following mechanisms in the pathogenesis:

(1) Free amine and intravenous lipid solutions may have caused retinal damage by accumulation in the ganglion cells, as they have already been described as causing neurological damage, including cortical blindness. ${ }^{12-15}$ It is worth noting that the macular involvement started to clear up 18 hours after cessation of the hyperalimentation.

(2) The low serum levels of $\mathrm{Zn}(30 \mu \mathrm{g} / 100 \mathrm{ml}$ $(300 \mu \mathrm{g} / \mathrm{l})$ and $\mathrm{Cu}(70 \mu \mathrm{g} / 100 \mathrm{ml}(700 \mu \mathrm{g} / \mathrm{l})$, which were accompanied by the development of follicular dermatitis, well known as being related to zinc deficiency, ${ }^{16}$ might be the reason for retinal damage. Both elements are essential to the structure and function of important enzymes such as uricose cytochrone oxidase, ascorbic acid oxydase, monoamine oxydase, thyrosinase, and for the synthesis of haemoglobin, proteins and nucleic acids. Therefore their deficiency seriously affects cellular metabolism. ${ }^{14}{ }^{16}$ Zinc is also essential for the metabolism of vitamin $\mathrm{A}$ and retinal binding protein. ${ }^{16}$

The low level of alkaline phosphatase by itself is not known to be responsible for any retinal damage, and it is always accompanied by low levels of zinc. ${ }^{17}$

The patient received supplementary $\mathrm{Cu}$ and $\mathrm{Zn}$ and the improvement in the macular appearance as well as in its function occurred side by side with the return of these trace elements to normal values. It is still unclear whether the present maculopathy developed as a part of the systemic Crohn's disease or whether it was due to one of the other possible 
mechanisms described above, or both in conjunction.

\section{References}

1 Knox DL, Boyless TM. Colitic arthritis. In: Mausolf FA, ed. The Eye and Systemic Disease. St Louis: Mosby, 1974: 275-7.

2 Billson FA, de Dombal FT, Watkinson G. Ocular complications of ulcerative colitis. Gut $1967 ; 8$ : 102-6.

3 Kern F Jr. Crohn's disease. In: Kersner JB, Shorter RG, eds. Inflammatory Bowel Disease. Philadelphia: Lea and Febeger, 1975: 127-30.

4 Beeken WL. Remediable defects in Crohn's disease. Arch Intern Med 1975; 135: 686-90.

5 Dubois DS, Rothschild J, Silverman A. The varied manifestation of Crohn's disease in children and adolescents. Am J Gastroenterol 1979; 69: 203-11.

6 Carbone JV, Brandenburg LL, Silverman SS. Regional enteritis. In: Krupp MA, Chatton MJ, eds. Current Medical Diagnosis and Treatment. California: Lange, 1978: 362.

7 Hopkins DJ, Horan E. Ocular disorders in a series of patients with Crohn's disease. Br J Ophthalmol 1974; 58: $732-7$.
8 Koreletz BI, Coles RS. Uveitis associated with ulcerative and granulomatous colitis. Gastroenterology 1967; 52: 78-82.

9 Huck D, Meythaler H. Ocular symptoms in Crohn's disease and ulcerative colitis. Klin Monatsbl Augenheilkd 1975; 166: 400-2.

10 Walsh FB, Hoyt WF. Clinical Neuro-ophthalmology. 3rd ed. Baltimore: Williams and Wilkins, 1968: 1: 191-830.

11 Ellis PP, Gentry JH. Ocular complications of ulcerative colitis. Am J Ophthalmol 1969; 58: 779.

12 Valdan R, Adar R. Hyperalimentation in cirrhotic patients. Harefuah 1977; 93: 363-5.

13 Jellinek EH. Dangers of intravenous fat infusions. Lancet 1976; ii: 967.

14 Fleming CR, McGill CS, Hoffman NH, Nelsen RA. Total parenteral nutrition. Mayo Clin Proc 1976; 51: 187-99.

15 Myers RN, Smink RD. Parenteral hyperalimentationfive years clinical experiment. Am J Gastroenterol 1979; 62: 313-24.

16 Abdallah M, Svanson S, Norden A. Cuprum and zinc. Scand J Gastroenterol 1979; 14: 168-75.

17 Fell GS, Burus RR. Zinc and other trace elements. In: Ivan DA J, ed. Advances in Parenteral Nutrition. Lancaster: MTP Press, 1978: 241-61. 